\title{
Efeito da inoculação de sementes com Azospirillum brasilense sobre o fracionamento nitrogenado e glicídico em silagens de sorgo
}

Effect of inoculation of seeds with Azospirillum brasilense on nitrogen and glycidic fractionation in sorghum silagens

Efecto de la inoculación de semillas con Azospirillum brasilense sobre el fraccionamiento de nitrógeno y glicídico en ensilajes de sorgo

Larissa Luísa Schumacher ORCID: https://orcid.org/0000-0002-7065-1787 Universidade Federal de Santa Maria, Brasil E-mail: larischumacher@hotmail.com Julio Viégas

ORCID: https://orcid.org/0000-0003-2169-9570 Universidade Federal de Santa Maria, Brasil E-mail: jviegas.ufsm@gmail.com Tiago João Tonin

ORCID: https://orcid.org/0000-0001-9455-1783 Universidade Federal de Santa Maria, Brasil E-mail: tiagojtonin@gmail.com

Stela Näetzold Pereira

ORCID: https://orcid.org/0000-0002-1734-303X Universidade Federal de Santa Maria, Brasil E-mail: snaetzold@gmail.com

Fernando Reimann Skonieski

ORCID: https://orcid.org/0000-0002-6493-1141 Universidade Tecnológica Federal do Paraná, Brasil E-mail:fskonieski@yahoo.com.br

Gilmar dos Santos Cardoso ORCID: https://orcid.org/0000-0003-1774-8587 Universidade Federal de Santa Maria, Brasil E-mail: cardoso-gilmar@bol.com.br

Ana Luiza Van Caeneghem da Hora ORCID: https://orcid.org/0000-0002-5245-4122 Universidade Federal de Santa Maria, Brasil E-mail: analuizadh.20@gmail.com Janaína Vargas Teixeira

ORCID: https://orcid.org/0000-0002-2912-7430 Universidade Federal de Santa Maria, Brasil E-mail:janainavargast@hotmail.com

Larissa Bordin Temp

ORCID: https://orcid.org/0000-0003-1003-7977 Universidade Federal de Santa Maria, Brasil E-mail: larissa_temp@hotmail.com

Beatriz dos Santos Nemoto

ORCID: https://orcid.org/0000-0002-1887-836X

Universidade Federal de Santa Maria, Brasil E-mail:beatriz.nemoto@acad.ufsm.br

\section{Resumo}

A inoculação com Azospirillum brasilense apresenta potencial de uso na cultura do sorgo (Sorghum bicolor [L.] Moench) pela possibilidade de alterar a fisiologia e morfologia das plantas. Neste sentido, o presente estudo tem por objetivo avaliar a influência da inoculação via semente com a bactéria promotora de crescimento da estirpe Azospirillum brasilense sobre a composição morfológica, parâmetros fermentativos, perdas nutricionais, frações nitrogenadas e de carboidratos em silagem de sorgo do híbrido AG 2005. O delineamento experimental foi o inteiramente casualizado, constituindo-se de dois tratamentos (com e sem inoculação), com quatro repetições de silos. O fracionamento nitrogenado, foi determinado conforme descrito por Licitra et al. (1996) e para mensurar o fracionamento dos carboidratos, foi avaliado de acordo com a metodologia proposta por Lanzas et al. (2007). As 
plantas inoculadas apresentaram menor porcentagem de colmo, mas houve maior participação de panícula mais grãos. O híbrido inoculado produziu silagem com menor teor de nitrogênio insolúvel em detergente ácido (NIDA) e nitrogênio insolúvel em detergente neutro (NIDN). Com relação ao fracionamento de carboidratos, as silagens de sorgo com inoculação diferiram significativamente em CHO (carboidratos totais) e CC (fibra indigestível) em relação ao controle. Sobre o fracionamento proteico, a fração indigestível (PC), a inoculação apresentou redução de 0,29 unidade percentuais quando comparado ao controle. Desta forma, a inoculação de sementes com A. brasilense pode ser uma alternativa viável, pois apresenta potencial de reduzir a fração de proteína e glicídios insolúvel e indigestível no trato gastrointestinal em silagens de sorgo.

Palavras-chave: Bactéria promotora de crescimento; Fitormônios; Carboidratos; Partição; Proteína.

\begin{abstract}
Inoculation with Azospirillum brasilense has potential for use in the cultivation of sorghum (Sorghum bicolor [L.] Moench) due to the possibility of altering the physiology and morphology of plants. In this sense, the present study aims to evaluate the influence of inoculation via seed with the growth promoting bacteria of the strain Azospirillum brasilense on the morphological composition, fermentative parameters, nutritional losses,strain on nitrogen and carbohydrate fractions in sorghum silage of the hybrid AG 2005. The experimental design was completely randomized, consisting in two treatments (with and without inoculation), with four replications of experimental silos. The nitrogen fractionation was determined as described by Licitra et al. (1996) and to measure the fractionation of carbohydrates, it was evaluated according to the methodology proposed by Lanzas et al. (2007). The inoculated plants showed a lower percentage of stalk, but there was a greater participation of panicles and more grains. The inoculated hybrid produced silage with a lower content of nitrogen insoluble in acid detergent (ADIN) and nitrogen insoluble in neutral detergent (NDIN). Regarding the fractionation of carbohydrates, the sorghum silages with inoculation differed significantly in $\mathrm{CHO}$ (total carbohydrates) and CC (indigestible fiber) in relation to the control. Regarding protein fractionation, the fraction $(\mathrm{CP})$ being indigestible, the inoculation showed a reduction of 0.29 percentage units when compared to the control. Thus, the inoculation of seeds with A. brasilense may be a viable alternative, as it has the potential to reduce the insoluble and indigestible protein and glycid fraction in the gastrointestinal tract in sorghum silages.
\end{abstract}

Keywords: Growth-promoting bacteria; Phytohormones; Carbohydrates; Partition; Protein.

\title{
Resumen
}

La inoculación con Azospirillum brasilense tiene potencial para su uso en el cultivo de sorgo (Sorghum bicolor [L.] Moench) debido a la posibilidad de alterar la fisiología y morfología de las plantas. En este sentido, el presente estudio tiene como objetivo evaluar la influencia de la inoculación vía semilla con las bacterias promotoras del crecimiento de la cepa Azospirillum brasilense sobre la composición morfológica, parámetros fermentativos, pérdidas nutricionales, fracciones de nitrógeno y carbohidratos en ensilaje de sorgo del híbrido AG 2005. El diseño experimental fue completamente al azar, consistente en dos tratamientos (con y sin inoculación), con cuatro repeticiones de silos experimentales. El fraccionamiento de nitrógeno se determinó según lo descrito por Licitra et al. (1996) y para medir el fraccionamiento de carbohidratos, se evaluó según la metodología propuesta por Lanzas et al. (2007). Las plantas inoculadas mostraron un menor porcentaje de tallo, pero hubo una mayor participación de panículas y más granos. El híbrido inoculado produjo ensilaje con menor contenido de nitrógeno insoluble en detergente ácido (NIDA) y nitrógeno insoluble en detergente neutro (NIDN). En cuanto al fraccionamiento de carbohidratos, los ensilajes de sorgo con inoculación difirieron significativamente en $\mathrm{CHO}$ (carbohidratos totales) y CC (fibra no digerible) en relación al testigo. En cuanto al fraccionamiento de proteínas, al ser la fracción (PC) indigerible, la inoculación mostró una reducción de 0,29 unidades porcentuales con respecto al control. Por lo tanto, la inoculación de semillas con A. brasilense puede ser una alternativa viable, ya que tiene el potencial de reducir la fracción de proteína y glicido insoluble e indigesta en el tracto gastrointestinal en ensilajes de sorgo.

Palabras clave: Bacterias promotoras del crecimiento; Fitohormonas; Carbohidratos; Dividir; Proteína.

\section{Introdução}

A cultura de sorgo (Sorghum bicolor [L.] Moench) é adequada para a ensilagem, pois apresenta baixa capacidade tampão, alto valor nutricional, boa produtividade de biomassa por área, menor custo de produção em relação ao milho, e uma grande adaptabilidade a ambientes diversos, por deter sistema radicular profundo e ramificado (Magalhães et al., 2003), principalmente em ambientes mais secos ou com risco de estiagens não muito prolongadas.

Além disso, por se tratar de gramínea de ciclo carbono C4, no qual possui como característica, boa resposta produtiva de biomassa para ensilagem, sobretudo, quando ocorre o fornecimento de elevadas doses de adubação nitrogenada. O que, 
determina grandes investimentos em fertilizantes nitrogenados, podendo resultar em perdas elevadas de nitrogênio $(\mathrm{N})$ por volatilização e lixiviação.

Para contribuir de forma positiva no aumento da produtividade e no incremento do valor nutricional da silagem é imprescindível à adoção de tecnologias que possam favorecer a produção de espécies forrageiras de forma mais econômica e sustentável. Dentre estas tecnologias, encontra-se o uso de inoculantes microbiológicos compostos por bactérias associativas, como as do gênero Azospirillum spp em plantas não leguminosas. Estes procariontes apresentam a capacidade de fixar biologicamente o nitrogênio atmosférico através da enzima nitrogenase (Hungria, 2011), reduzindo-o em $\mathrm{NH}_{4}{ }^{+}$, sendo que nesta forma, as plantas são capazes de absorvê-lo (Marchetti \& Barp, 2015).

O gênero Azospirillum spp pode estimular a produção de fitohormônios, como auxinas, giberilinas e citocininas (Hungria, 2011). Estes, são capazes de proporcionar maior desenvolvimento das raízes, auxiliando na maior absorção de água e nutrientes (Nakao et al., 2018). Ocasionando alterações nas estruturas morfológicas e reprodutivas, bem como a histologia dos tecidos vegetais (Hungria et al., 2010). Resultando em plantas com qualidade nutricional superior, com potencial de garantir maior eficiência na produção de silagens.

Apesar dos efeitos promissores da inoculação com Azospirillum spp, em relação à produção de biomassa e uma maior proporção de grãos em gramíneas como milho, trigo e arroz (Repke et al., 2013), em sorgo para ensilagem, entretanto, poucos são os relatos encontrados na literatura. Principalmente, em relação, ao efeito da inoculação sobre a partição proteica e glicídica nas silagens de sorgo, em vista que a inoculação é capaz de apresentar alterações nos parâmetros fisiológicos e morfológicos das plantas (Skonieski et al., 2019).

Neste sentido, caracterizar de forma detalhada o fracionamento de proteína e de carboidratos das silagens através do modelo mecanicista Cornel Net Carbohydrate and Protein System (CNCPS), em relação à bromatologia usual, permite predizer de maneira mais realista a estimativa das características físicas, químicas, degradação ruminal e características de digestibilidade pós-ruminal, além de poder avaliar as interações planta-animal.

Nesta perspectiva, o presente estudo tem como intuito avaliar a influência da inoculação de sementes com estirpes de Azospirillum brasilense sobre sobre a composição morfológica, parâmetros fermentativos, perdas nutricionais, fracionamento de proteína e de carboidratos em silagem de sorgo.

\section{Metodologia}

O experimento foi conduzido pelo Grupo de Estudo em Aditivos na Produção Animal (GEAPA) da UFSM, no período compreendido entre novembro de 2017 a abril de 2018. A área experimental foi instalada na cidade de Santa Maria RS, Brasil, coordenadas latitude -29,73'12'" Sul e longitude 53.71'82" Oeste. O solo da região é classificado como Argissolo Vermelho Distrófico (horizontes A e Bt definidos) (Embrapa, 2013). O clima é osubtropical, sem estação seca e com verões quentes (Peel et al., 2007). No mês de maio de 2016 foi realizada semeadura de Avena sativa L. para obtenção de cobertura de solo para o plantio direto, na primavera.

Utilizou-se o híbrido de sorgo comercial Agroceres AG2005, em que, momentos antes da semeadura, as sementes foram inoculadas, à sombra, com bactérias da espécie Azospirillum brasilense, estirpes Ab-V5 e Ab-V6 isoladas por Hungria et al. (2010) na concentração de $2,0 \times 10^{8}$ UFC mL $^{-1}$ com a utilização de $200 \mathrm{~mL} \mathrm{ha}^{-1}$ de inoculante (Aztotal ${ }^{\circledR}$ - Total

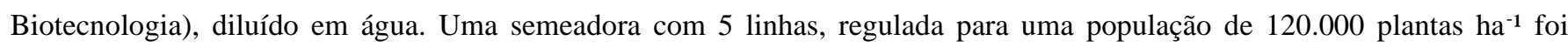
utilizada para semeadura. Durante o desenvolvimento da cultura, foram realizadas duas adubações de cobertura com N, divididas nos estágios V4 e V8, totalizando $180 \mathrm{~kg} \mathrm{ha}^{-1} \mathrm{de} \mathrm{N}$, à base de ureia, para ambos os tratamentos testados. Para o controle de ervas daninhas, foi realizada a capina manual das parcelas. 
Quando o híbrido apresentou 30\% de MS, as plantas foram cortadas a uma altura média de $20 \mathrm{~cm}$ do solo, trituradas em partículas de tamanho médio de $2 \mathrm{~cm}$, ensiladas em mini silos experimentais. No momento da confecção da ensilagem, a biomassa foi adequadamente compactada e a silagem foi hermeticamente fechada com quatro sacos plásticos, assim os silos experimentais continham $6 \mathrm{Kg}$ de silagem.

Após 120 dias de fermentação os silos foram abertos, sendo descartada uma a camada superior de silagem e amostras de $200 \mathrm{~g}$ de silagem fresca foram retiradas do centro destes. Realizou-se a pesagem do conjunto composto por saco, areia e silagem e separadamente de cada um dos componentes, para determinação das perdas por efluentes (PE), perdas por gases (PG) e a recuperação da MS (RMS) da silagem conforme Jobim et al. (2007). Uma das amostras retiradas (200 gramas) foi prensada utilizando prensa hidráulica (Carver, Model C). Uma alíquota do líquido extraído da prensa foi utilizada para mensurar o $\mathrm{N}$ amoniacal $\left(\mathrm{NH}_{3}\right)$ pelo método fenol-hipoclorito (Weatherburn,1967) e no restante do líquido foi medido o $\mathrm{pH}$ conforme Silva \& Queiroz (2002).

$\mathrm{O}$ restante das amostras foram secas em estufa a $55{ }^{\circ} \mathrm{C}$ por tempo mínimo de 72 horas e então pesadas para determinação da matéria parcialmente seca (MPS), posteriormente moídas em moinho de crivos do tipo "Willey", com peneira de $1 \mathrm{~mm}$ para as análises químicas, as quais foram realizando-se todas as análises bromatológicas no Laboratório de Bromatologia e Nutrição de Ruminantes da UFSM. A matéria seca total (MS) foi determinada em estufa a $105{ }^{\circ} \mathrm{C}$ durante um período mínimo de 8 horas, a matéria mineral (MM) através de incineração em mufla a $550{ }^{\circ} \mathrm{C}$ durante 4 horas.

A análise de extrato etéreo (EE) foi realizada de acordo AOCS (2005). A determinação da proteína bruta (PB) foi estimada pela destilação do N, pelo método micro Kjeldahl e multiplicando o valor de N encontrado por 6,25 (AOAC, 1995). A avaliação dos níveis de $\mathrm{N}$ insolúvel em detergente neutro (NIDN), $\mathrm{N}$ insolúvel em detergente ácido (NIDA), $\mathrm{N}$ solúvel, a determinação de $\mathrm{N}$ não proteico (NNP), assim como as equações utilizadas para calcular o fracionamento de $\mathrm{N}$, foram determinados conforme Licitra et al. (1996). Os compostos nitrogenados foram classificados de acordo com a degradação ruminal, composição química e digestibilidade pós ruminal, sendo representado pelas frações A, B1, B2, B3 e C.

A Fração $\mathrm{A}$ = representada pelos componentes nitrogenados de natureza não proteica (NNP); Fração B1 = proteína solúvel em tampão borato-fosfato, mas que precipita em solução de ácido tricloroacético (TCA), possuindo taxa altas de degradação no rúmen, sendo que a equação utilizada foi: NNP- N solúvel; Fração B2: proteína insolúvel em tampão - borato presente no conteúdo celular, e apresenta taxa de degradação intermediária, em que a fórmula utilizada foi: NIDN - N insolúvel; Fração B3: proteína potencialmente degradável existente na parede celular das plantas, sendo lentamente degradada no rúmen, calculando-se pela seguinte equação: NIDN- NIDA. Já a fração C: proteína que está ligada ao FDA e não é degradada no rúmen, no qual utilizou-se a determinação da análise de NIDA.

Os níveis de fibra em detergente neutro (FDN) foram obtidos com a utilização de $\alpha$-amilase termoestável (Termamyl 120 L, Novozimes Latin America, LTDA) e com equipamento de autoclave, conforme a técnica descrita por Senger et al. (2008). O teor de fibra em detergente ácido (FDA) e o teor de lignina foram obtidos de acordo com a metodologia descrita por Van Soest et al. (1991), sendo a lignina extraída com o uso de ácido sulfúrico 72\%. Os teores de hemicelulose e celulose foram obtidos considerando as diferenças entre os teores de FDN e FDA e os de FDA e lignina, respectivamente.

Para os ácidos graxos voláteis, a preparação das amostras de ácido acético, propiônico e butírico foi realizada de acordo com o método descrito por Tangerman \& Nagengast (1996), enquanto o ácido lático foi submetido ao processo de derivatização com o auxílio de N-terc-butildimetilsilil- N-metiltrifluoroacetamida de acordo com o método descrito por OmsOliu et al. (2011). Posteriormente, as concentrações de todos os ácidos foram analisadas por cromatografia gasosa equipada com detector de ionização por chama Varian Star 3400 CX (GC-FID; CA, EUA).

Os açúcares solúveis foram determinados usando o método colorimétrico fenol-sulfúrico conforme descrito por Hall (2000). A determinação do amido foi realizada pelo método proposto por Walter et al. (2005) que inclui digestão enzimática 
sequencial com amilase (Termamyl 120 L), amiloglicosidase (AMG 300 L) e protease (Flavourzyme 500 L) para hidrólise de amido e proteína. Os açúcares resultantes dessa digestão foram quantificados em espectrofotômetro e com absorbância de $\lambda=$ $505 \mathrm{~nm}$, utilizando o kit glicose oxidase peroxidase como reagente de cor.

O fracionamento dos carboidratos foi realizado de acordo com a metodologia descrita por Lanzas et al. (2007). As frações foram divididas em $\mathrm{CHOT}=$ carboidrato total $(\mathrm{CHOT}=\mathrm{PB}-\mathrm{EE}-\mathrm{CZ}) ; \mathrm{CNF}=$ carboidrato não fibroso $(\mathrm{CHOT}-\mathrm{B} 3$ C); $\mathrm{A} 1=$ soma dos ácidos graxos voláteis (ácidos acético, propiônico, butírico e isobutírico), A2= ácido lático; A4= açúcar solúvel; B1= amido; B2= fibra solúvel $(\mathrm{CNF}-\mathrm{A} 1-\mathrm{A} 2-\mathrm{A} 3-\mathrm{A} 4-\mathrm{B} 1)$; B3= fibra digestível $($ FDN $-(\mathrm{NIDIN} * \mathrm{~PB}) / 1000-$ C) e fração C = fibra indigestível $($ FDN $\times$ Lignina $\times 2.4 / 1000)$.

$\mathrm{O}$ delineamento experimental utilizado foi o inteiramente casualizado, com dois tratamentos (inoculado e controle) e quatro repetições cada. Os dados foram submetidos à análise de variância (ANOVA), para comparação entre as médias, utilizou-se o teste $\mathrm{F}$. As diferenças foram declaradas significativas em $\mathrm{P} \leq 0,05$, sendo realizado com o uso do programa estatístico SAS, versão SAS® University Edition.

\section{Resultados e Discussão}

Na Tabela 1, podemos observar que a inoculação promoveu incremento de 10,62\% para a panícula mais grão, em relação ao controle. Para a variável colmo, a inoculação diminuiu 7,4\%, quando comparado ao tratamento controle. Já para os demais componentes, a inoculação não causou efeito.

Tabela 1 - Valores da composição morfológica das plantas de sorgo, com base na matéria seca.

\begin{tabular}{ccccc}
\hline Componentes (\%) & Controle & Inoculado & EPM & Pr $>$ F \\
\hline Folha & 14,61 & 13,51 & 1,02 & 0,524 \\
Colmo & 58,66 & 51,26 & 1,89 & 0,031 \\
Material Senescente & 15,34 & 14,00 & 0,09 & 0,633 \\
Panícula + Grão & $11,38^{\mathrm{B}}$ & $22,00^{\mathrm{A}}$ & 1,93 & 0,032 \\
\hline
\end{tabular}

Médias seguidas por letras maiúsculas distintas na mesma linha apresentaram diferença significativa pelo teste $\mathrm{F}(\mathrm{P}<0,05)$.

EPM: Erro Padrão da Média

Fonte: Autores

Colmos mais desenvolvidos podem armazenar uma maior quantidade de substâncias orgânicas e inorgânicas (Nakao et al., 2014) entretanto, a diminuição causada pela inoculação no estudo atual, causou efeito na diminuição de forma favorável dos componentes da parede celular de menor digestibilidade.

Ao estudar o efeito da inoculação, associado com diferentes aplicações de $\mathrm{N}$ sobre a cultura do sorgo, Mortate et al. (2020), relataram que houve maior rendimento no número de grãos por panícula, que por consequência apresentou aumento na produtividade da cultura. Do mesmo modo, no presente estudo, o inoculante também incrementou a estrutura da panícula e do grão. Tal efeito, pode ser justificado em parte, pelo incremento no processo de absorção de nutrientes do solo, associando-se com o maior desenvolvimento da panícula (Hungria, 2010). Sendo que o inoculante pode apresenta potencial promissor em incrementar a produção nas mais diferentes forrageiras, podendo impactar positivamente no fracionamento glicídico e proteico nas silagens de sorgo.

A inoculação causou efeito na elevação de $1,48 \%$ para o EE, quando comparado ao tratamento controle, incrementando desta forma, o nível energético da silagem. Tal fato, também foi observado no estudo de Skonieski et al. (2017), em que a inoculação com Azospirillum brasilense aumentou, embora sutilmente, os teores de EE em 0,14\%. Entretanto, mesmo que a inoculação apresenta efeito sobre o conteúdo do EE das silagens de sorgo, o motivo para tal elevação ainda não é bem compreendida.A inoculação das sementes com Azospirillum brasilense reduziu a quantidade de NIDA e 
NIDIN ( $\mathrm{P}<0,05)$, mas não foram observadas mudanças significativas nas demais variáveis (Tabela 2). A menor participação de NIDA nas silagens de plantas inoculadas, resultou em redução de $14 \%$ em relação às plantas do tratamento controle. Demonstrando que, a inoculação apresenta capacidade de modificar beneficamente a formação da parede celular das plantas de sorgo.

Tabela 2 - Composição química, parâmetros fermentativos e as perdas nutricionais das silagens de sorgo, submetidas ou não à noculação com A. brasiliense.

\begin{tabular}{|c|c|c|c|c|}
\hline \multirow{2}{*}{ Variáveis } & \multicolumn{2}{|c|}{ Tratamento } & \multirow[b]{2}{*}{ EPM } & \multirow[b]{2}{*}{$\operatorname{Pr}>F$} \\
\hline & Controle & Inoculado & & \\
\hline MS (\%) & 31,08 & 31,60 & 0,31 & 0,457 \\
\hline $\mathrm{MO}(\% \mathrm{MS})$ & 94,65 & 94,49 & 0,09 & 0,426 \\
\hline $\mathrm{MM}(\% \mathrm{MS})$ & 5,34 & 5,50 & 0,09 & 0,423 \\
\hline $\mathrm{EE}(\% \mathrm{MS})$ & 3,20 & 4,68 & 0,34 & 0,011 \\
\hline FDN (\% MS) & 58,93 & 59,80 & 0,75 & 0,606 \\
\hline FDA (\% MS) & 38,06 & 38,69 & 0,45 & 0,654 \\
\hline LDA (\% MS) & 6,27 & 5,57 & 0,23 & 0,138 \\
\hline $\mathrm{PB}(\% \mathrm{MS})$ & 5,78 & 5,95 & 0,09 & 0,395 \\
\hline $\mathrm{PS}(\% \mathrm{~PB})$ & 37,66 & 42,63 & 2,74 & 0,403 \\
\hline NIDA (\% PB) & $10,26^{\mathrm{A}}$ & $5,05^{\mathrm{B}}$ & 1,34 & 0,032 \\
\hline NIDIN (\% PB) & $19,76^{\mathrm{A}}$ & $15,73^{\mathrm{B}}$ & 1,05 & 0,041 \\
\hline $\mathrm{Ph}$ & 3,91 & 3,93 & 0,01 & 0,405 \\
\hline RMS (\% MS) & 97,48 & 97,88 & 0,17 & 0,274 \\
\hline PE & 0,90 & 0,99 & 0,06 & 0,551 \\
\hline PG & 0,05 & 0,05 & 0,02 & 0,638 \\
\hline $\mathrm{NH} 3-\mathrm{N}$ & 8,01 & 7,24 & 0,30 & 0,242 \\
\hline DENSIDADE $\left(\mathrm{Kg} / \mathrm{m}^{3}\right)$ & 430,00 & 441,81 & 0,09 & 0,427 \\
\hline
\end{tabular}

Médias seguidas por letras maiúsculas distintas na mesma linha apresentaram diferença significativa pelo teste $\mathrm{F}(\mathrm{P}<0,05)$.

EE: Extrato Etéreo; EPM: Erro Padrão da Média; FDA: Fibra em Detergente Ácido; FDN: Fibra em Detergente Neutro; MO: matéria orgânica; MM: Matéria Mineral; MS: Matéria Seca; NH3-N: \% de Nitrogênio Amoniacal, em relação ao nitrogênio total; NIDA: Nitrogênio Insolúvel em Detergente Ácido, NIDIN: Nitrogênio Insolúvel em Detergente Neutro; PB: Proteína Bruta; PE: Perdas por Efluentes; PG: Perdas por Gases; PS: Proteína Solúvel; RMS: Recuperação da Matéria Seca.

Fonte: Autores

Houve efeito da inoculação sobre os CHO na silagem de sorgo, obtendo uma redução de $1,85 \%$ sobre o tratamento controle (Tabela 3). Os carboidratos das forragens são substratos essenciais para ocorrer adequada fermentação pelos microrganismos envolvidos no processo de ensilagem. Ademais, os valores de $\mathrm{CHO}$ obtidos neste estudo são superiores daqueles relatados por Van Soest (1994) e Viana et al. (2012) no qual, relatam teores de 50 a 80\% e 78,7 \% da MS em silagens de sorgo, respectivamente. 
Tabela 3 - Efeito da inoculação ou não com a bactéria Azospirillum brasilense sobre a fração dos carboidratos da silagem de sorgo.

\begin{tabular}{ccccc}
\hline \multirow{2}{*}{$\begin{array}{c}\text { Fração CHO } \\
(\% \text { MS })\end{array}$} & \multicolumn{2}{c}{ Tratamento } & EPM & Pr >F \\
\cline { 2 - 4 } CHOT & 85,79 & Inoculado & 0,45 & 0,009 \\
CNF & 26,09 & 83,84 & 0,80 & 0,292 \\
CA1 & 1,84 & 24,07 & 0,28 & 0,798 \\
CA2 & 3,50 & 1,79 & 0,70 & 0,583 \\
CA4 & 4,27 & 2,99 & 0,54 & 0,386 \\
CB1 & 6,96 & 3,55 & 2,50 & 0,549 \\
CB2 & 9,20 & 7,10 & 1,03 & 0,540 \\
CB3 & 51,02 & 8,51 & 1,50 & 0,123 \\
CC & $11,26^{\mathrm{A}}$ & 48,52 & 2,15 & 0,016
\end{tabular}

Médias seguidas por letras maiúsculas distintas na mesma linha apresentaram diferença significativa pelo teste $\mathrm{F}(\mathrm{P}<0,05)$.

EPM: erro padrão da média; $\mathrm{CHOT}=$ carboidrato total, $\mathrm{CNF}=$ carboidrato não fibroso, CA1 = soma dos ácidos voláteis (acético, propiônico, butírico e isobutírico), $\mathrm{CA} 2$ = ácido láctico, $\mathrm{CA} 3=$ outros ácidos orgânicos, $\mathrm{CA} 4=$ açúcares solúveis, $\mathrm{CB} 1=$ amido, $\mathrm{CB} 2=$ fibra solúvel, $\mathrm{CB} 3=$ fibra digestível, $\mathrm{CC}=$ fibra indigestível.

Fonte: Autores

Os teores de CNF, deste estudo, não sofreram alterações quando inoculados, observando-se o teor médio de $25,58 \%$ MS. No entanto, pesquisas tem demonstrado que a inoculação com A. brasilense, é capaz de proporcionar maior acúmulo de matéria seca, carboidratos solúveis em detergente neutro e quantidade de grãos. E isso ocorre através da produção de hormônios vegetais capazes de alterar a morfologia da planta, permitindo o aumento da absorção de nutrientes, pelo maior número de radicelas e o diâmetro das raízes absorventes (Almeida et al., 2021; Cassàn \& Dias-Zorita, 2016).

Em relação ao fracionamento de carboidratos expandido proposto por Lanzas et al. (2007), realizado no presente estudo, a inoculação não alterou as frações de CA1, CA2, CA4, apresentando média de 1,81\%, 3,24\% e 3,91\%, respectivamente.

Pode-se verificar que a fração CB1, composta pelo amido não respondeu à inoculação, apresentando valores semelhantes ao controle. Entretanto, o teor de amido observado foi considerado baixo (7,03 \% MS), quando comparado ao valor médio de amido em silagens de sorgo, que gira em torno de 30 \% MS (Fox et al., 2004). Tal fato, pode ser explicado em parte, pela ocorrência dos ataques de pássaros que as plantas sofreram durante o seu período de cultivo nas áreas experimentais, o que resultou em redução na produção de grãos. Este problema é recorrente, causando graves prejuízos aos produtores.

A fração CB2, composta pelas fibras solúveis não sofreu efeito da inoculação. Esta fração fermenta rapidamente, com taxas de degradação ruminal que variam de 0,20 a $0,40 \%$ h de acordo com CNCPS, sendo observado teores médios de $8,85 \%$ MS. Em relação a fração CB3, representada pelas fibras digestíveis, não foi alterada com a inoculação das sementes, sendo observado o teor médio de 49,77 \% MS. Sendo que esta fração tem uma taxa de degradação lenta, e representa a fração fibrosa da planta, como o FDN e FDA que normalmente afetam o consumo animal pelo fator enchimento, reduzindo o desempenho dos animais (Detmann et al., 2014).

Em contrapartida, estudos como de Skonieski et al. (2017), avaliando os efeitos da inoculação com A brasilense sobre a produtividade e qualidade da silagem de milho, observaram um aumento na energia da silagem (NDT) e uma redução da fibra (FDA). Os autores justificaram essa alteração em decorrência das modificações sofridas nos tecidos vegetais, como na deposição de células do mesófilo, parênquima, esclerênquima, o qual possuem diferentes concentrações de parede e conteúdo 
celular. Isso provoca mudanças na composição da planta, como nos teores de PB, carboidratos (estruturais e solúveis), além afetar o teor energia.

Já a fração C, ou seja, fibra indigestível, está associada à fração de lignina, sendo a fração que não é degradada pelo animal, sofreu alteração positiva com a inoculação, em que ocorreu diminuição de 3,58\% em relação ao controle. Neste sentido, podemos destacar a importância de realizar a inoculação em plantas de sorgo, visto que ela tem efeito em diminuir a fração indigestível, melhorando desta forma, o valor nutricional da silagem de sorgo.

Na tabela 4, podemos verificar que a inoculação não alterou a PB das silagens de sorgo, com média de 5,87\% na MS. Os valores de PB observados, segundo Van Soest (1994), são considerados baixos, pois não apresentam nível adequado para atender às exigências mínimas para o crescimento, mantença da flora ruminal e síntese de proteína microbiana. Na avaliação do perfil fermentativo e composição bromatológica de silagens de sorgo em resposta à adubação nitrogenada, Macedo et al. (2012), também relataram médias inferiores (5,59 \% PB), semelhantes ao presente estudo.

Tabela 4 - Composição da fração proteica das silagens de sorgo, híbrido AG 2005, obtidas na inoculação de sementes, ou não, com Azospirillum brasilense.

\begin{tabular}{|c|c|c|c|c|}
\hline \multirow{2}{*}{$\begin{array}{c}\text { Fração Proteica } \\
\text { (\% MS })\end{array}$} & \multicolumn{2}{|c|}{ Tratamentos } & \multirow[b]{2}{*}{ EPM } & \multirow[b]{2}{*}{$\operatorname{Pr}>\mathrm{F}$} \\
\hline & Controle & Inoculado & & \\
\hline $\mathrm{PB}$ & 5,77 & 5,95 & 0,19 & 0,397 \\
\hline PA & 2,07 & 2,39 & 0,20 & 0,254 \\
\hline PB1 & 0,10 & 0,12 & 0,01 & 0,254 \\
\hline PB2 & 2,46 & 2,86 & 0,13 & 0,121 \\
\hline PB3 & 0,55 & 0,63 & 0,06 & 0,581 \\
\hline $\mathrm{PC}$ & $0,59^{\mathrm{A}}$ & $0,30^{\mathrm{B}}$ & 0,09 & 0,046 \\
\hline
\end{tabular}

Médias seguidas por letras maiúsculas distintas na mesma linha apresentaram diferença significativa pelo teste $\mathrm{F}(\mathrm{P}<0,05)$. EPM: erro padrão da média; $\mathrm{PB}=$ Proteína Bruta; $\mathrm{PA}=$ Nitrogênio Não Proteico; $\mathrm{PB} 1=$ Degradação Rápida; $\mathrm{PB} 2=$ Degradação Intermediária; $\mathrm{PB} 3=$ Degradação Lenta; $\mathrm{PC}=$ Indigestível.

Fonte: Autores

O teor de PB em silagens de gramíneas é bastante variável, sendo dependente das características individuais de cada genótipo, além de estar relacionado diretamente com a adubação nitrogenada em cobertura. Vale ressaltar, que diferente do que ocorre em leguminosas, durante a associação entre as bactérias e as gramíneas, somente uma parte do $\mathrm{N}$ pode ser fornecida para a planta, sendo a adubação nitrogenada em cobertura importante para obter altos rendimentos e maior porcentagem de PB nas silagens (Skonieski et al., 2017).

Reconhecendo a importância de realizar o fracionamento dos alimentos, isto é, compreender melhor a variação química e física, bem como a fermentação ruminal e a otimização dos modelos de predição de resposta do animal, a fração PA, composta pelo $\mathrm{N}$ não proteico da silagem, no qual apresenta rápida solubilização ruminal, não foi observada alteração significativa entre os tratamentos testados, obtendo média de 2,23\% aos 120 dias de fermentação.

Em relação ao processo fermentativo da silagem, grande parte da proteína disponível é convertida naturalmente em NNP, através da desaminação de proteínas. Entretanto, altos índices de NNP na silagem podem ser indicativos de crescimento de microrganismos indesejáveis como os clostrídios e leveduras, acarretando na depressão do valor nutricional da silagem. Na avaliação de Viana et al. (2012) relataram valores superiores em comparação ao presente estudo para a fração A, com média de $13,7 \%$ em N total (NT) na silagem de sorgo. 
No que se refere à fração PB1, é a parte da PB solúvel rapidamente degradada no rúmen, apresentando uma taxa teórica de degradação de 1,2 a $4 \%$ h. No presente estudo, a inoculação não demonstrou efeito, sobre a fração PB1, apresentando valor médio de $0,11 \%$ na MS. Vale ressaltar que, quando a disponibilidade de proteínas do alimento que apresenta degradação rápida é elevada, é importante suprir concomitantemente alimentos com carboidratos que também apresentem rápida degradação, para que assim, possa ocorrer o perfeito sincronismo de formação de proteína microbiana (Van Soest, 1994).

A fração PB2, proteína insolúvel em FDN com taxa de degradação intermediária $(0,03$ a $0,16 \% / \mathrm{h})$, não sofreu efeito da inoculação, sendo observada média de 2,66\% na MS. Viana et al., (2012) utilizaram em seu trabalho a soma da fração de degradação rápida e intermediária (PB1+PB2), relatando uma média de 59,5 \% em NT. Destaca-se também que a fração PB1 e PB2, são consideradas por Sniffen et al. (1992) a porção de proteína verdadeira disponível para os microrganismos ruminais.

A fração PB3, representada pela proteína insolúvel em FDN, também podendo ser reconhecida como NIDN, demonstra uma lenta degradação, por volta de 0,0006-0,0055 \%/h. Como observado na Tabela 1, não teve efeito significativo, atingindo uma média entre os tratamentos de 0,59\% na MS. No estudo de Naeini et al. (2014), observaram que aos 60 dias de fermentação a média de NIDN foi de $253 \mathrm{~g} / \mathrm{kg}$ PB.

Já a fração PC, conhecida como NIDA, ao qual também pode ser relacionado ao $\mathrm{N}$ ligado à lignina e taninos das forrageiras, não é degradada no rúmen, isto é, a taxa de degradação é nula (Sniffen et al., 1992; Pires et al., 2009). No presente estudo, a inoculação causou efeito na redução na fração PC, da ordem de 0,29 unidade percentuais. Fato este, de grande relevância, uma vez que, quanto menor for a quantidade de NIDA em silagens, melhor é a sua qualidade nutricional, no qual, associa-se com o resultado da diminuição de NIDA na Tabela 1. Esta redução na fração PC demonstra que a inoculação apresenta capacidade de modificar a estrutura anátomo-histológica da parede celular, através do aumento da produção de enzimas, além disso, se torna relevante observar estas alterações para poder maximizar as estimativas de produção de leite ou carne.

Entretanto, com base nestes resultados, ainda não é possível obter uma conclusão definitiva sobre o efeito da inoculação em relação ao fracionamento proteico e glicídico da silagem de sorgo. Porém, a literatura é farta em apontar que, a inoculação estimula uma série de reações bioquímicas entre raízes e bactérias. Deve-se considerar também que o clima, tipo de solo, $\mathrm{pH}$, umidade, a competição com a microbiota nativa e o genótipo também podem interferir na adaptação das bactérias inoculadas, acarretando inconstâncias nos resultados encontrados (Almeida et al., 2021; Quadros et al., 2014).

\section{Conclusão}

Sobre a morfologia das plantas, reduziu a porcentagem de colmos, mas aumentou a participação de panículas mais grãos na silagem. A inoculação com Azospirillum brasilense em sementes de híbridos de sorgo foi eficiente em promover incremento no teor de EE e na diminuição de NIDA E NIDIN.

No fracionamento de carboidratos, a inoculação houve diminuição de CHO e na fração CC. Em relação ao fracionamento proteico, a inoculação causou redução na fração PC. Com a inoculação nas sementes é possível obter silagens com menor teores de frações indigestíveis, podendo desta forma, melhorar o perfil nutricional do material ensilado.

\section{Agradecimentos}

Agradecemos à Coordenação de Aperfeiçoamento de Pessoal de Nível Superior (CAPES) pela bolsa concedida ao primeiro autor. 


\section{Referências}

Almeida, L. S., Sobrinho, S. P., Luz, P. B., Caldeira, D. S. A., Oliveira, A. J., Vilarinho, M. K. C., Vieira, C. L., Silva, A. S. P., Silva, G. V. B. (2021). Uso de inoculante Azospirillum brasilense na produção de mudas de Tento Carolina. Research, Society and Development, 10, (1), 1-9. 0.33448/rsd-v10i1.11469

AOAC- Association of Official Analytical Chemists (1995). Official methods of analysis. (16th ed.), AOAC International, Arlington.

Cassán, F.,Diaz-Zorita, M.(2016).Azospirillum sp. In current agriculture: From the laboratory to the field. Soil Biology \& Biochemistry,103, 117-130. 10.1016/j.soilbio.2016.08.020

CNCPS- Cornell Net Carbohydrate and Protein System- Ithaca. (2002).: Cornell University, Software, version 5.0, fromhttps://www.yumpu.com/en/document/view/28012541/the-net-carbohydrate-and-protein-system-for-evaluating-herd-nutrition-

Detmann, E., Gionbelli, M. P., Huhtanen, P. (2014) A meta-analytical evaluation of the regulation of voluntary intake in cattle fed tropical forage-based diets. Journal of Dairy Science, 92, 4632-4641. 10.2527/jas.2014-7717

Embrapa. Empresa Brasileira de Pesquisa Agropecuaria. (2013). Sistema brasileiro de classificação de solos, (3a ed.), Brasília - DF, 353, fromhttps://www.embrapa.br/busca-de-solucoes-tecnologicas/-/produto-servico/1299/sistema-brasileiro-de-classificacao-de-solos---sibcs-3-edicao

Fox, D. Tedeschi, L., Van Amburgh, M., Tylutki, T. P. (2004). The Cornell Net Carbohydrate and Protein System model for evaluating herd nutrition and nutrient excretion. Animal Feed Science and Technology, 112, 29-78.10.1016/j.anifeedsci.2003.10.006

Hall, M. B. Neutral detergent-soluble carbohydrates: nutritional relevance and analysis - a laboratory manual. (2000). University of Florida Extension Extension, Institute of Food and Agricultural Sciences, 339. https://animal.ifas.ufl.edu/media/animalifasufledu/dairy/pdf/Manual_-_Neutral_DetergentSoluble_Carbohydrates_Nutritional_Relevance_and_Analysis.pdf

Hungria, M. (2011). Inoculação com Azospirillum brasilense: inovação em rendimento a baixo custo. Embrapa Soja - Documentos 325,, from https://www.embrapa.br/busca-de-publicacoes/-/publicacao/879471/inoculacao-com-azospirillum-brasilense-inovacao-em-rendimento-a-baixo-custo

Hungria, M., Campo, R. J. Souza, E. M., Pedrosa, F. O. (2010) Inoculation with selected strains of Azospirillum brasilense and A. Lipoferum improves yields of maize and wheat in Brazil. Plant and Soil, 331, 413-425. 10.1007/s11104-009-0262-0

Jobim, C. C. Nussio, L. G., Reis, R. A., Schmidt, P (2007). Avanços metodológicos na avaliação da qualidade da forragem conservada. Revista Brasileira de Zootecnia, 36, suplemento especial, 101-119. 10.1590/S1516-35982007001000013

Lanzas, C., Tedeschi, L. O., Seo, S. E Fox, D. G. (2007). Evaluation of protein fractionation systems used in formulating rations for dairy cattle. Journal of Dairy Science, 90, 507-521. 10.3168/jds.S0022-0302(07)72653-X

Licitra, G., Hernandez, T. M., Van Soest, P. J. (1996). Standardization of procedures for nitrogen fractionation of ruminant feeds. Animal Feed Science and Technology, 57, (4), 347-358. 10.1016/0377-8401(95)00837-3

Macedo,C. H. O., Andrade, A. P., Santos, E. M., Silva, D. S., Silva, T. C., Edvan, R. L. (2012). Perfil fermentativo e composição bromatológica de silagens de sorgo em função da adubação nitrogenada. Revista Brasileira de Saúde e Produção Animal, 13, (2), 371-382. 10.1590/S1519-99402012000200007

Magalhães, P. C., Durães, F. O. M., Rodrigues, J.A.S. (2003). Fisiologia da planta de sorgo. Sete Lagoas: Ministério da Agricultura, Pecuária e Abastecimento. 4p, from https://www.infoteca.cnptia.embrapa.br/infoteca/handle/doc/487527

Marchetti, M. M., Barp, E. A. (2015). Efeito rizosfera: a importância de bactérias fixadoras de nitrogênio para o solo/planta - revisão. Ignis, 4, (1), 61-71, from https://periodicos.uniarp.edu.br/index.php/ignis/article/view/767/474

Mortate, R. K., Nunes, B. M., Costa, R. M., Rocha, E. M. F. (2020). Rresposta de sorgo inoculado com azospirillum brasilense a doses de nitrogênio em cobertura. Ciência Agrícola, Rio Largo, 18, (1), 65-72, from https://www.seer.ufal.br/index.php/revistacienciaagricola/article/view/7388/7354

Naeini, S. Z., Emami, N. K., Rowghani, E., Bayat, A. (2014). Influence of ensiling time on chemical composition, fermentation characteristics, gas production and protein fractions of sweet sorghum silage. Research Opinions in Animal \& Veterinary Sciences, 4, (6), 286-293. http://www.roavs.com/.../286-293.pdf

Nakao, A. H., Andreotti, M., Soares, D. A., Modesto, V. C. Dickmann, L. (2018). Intercropping Urochloa brizantha and sorghum inoculated with Azospirillum brasilense for silage. Revista Ciência Agronômica, 49, (3), 501-511. 10.5935/1806-6690.20180057

Nakao, A. H., Souza, M. F. P., Dickmann, L., Centeno, D. C., Rodrigues, R. A. F. (2014) Resposta do sorgo granífero à aplicação de diferentes doses e épocas de inoculante (azospirillum brasilense) via foliar. Enciclopédia Biosfera, Centro Científico Conhecer, 10, (18), 2702-2714, http://www.conhecer.org.br/enciclop/2014a/AGRARIAS/Resposta\%20do\%20sorgo.pdf

Oms-Oliu, G., Hertog, M. L. A. T. M., Van De Poel, B., Ampofo-Asiama, J., Geeraerd, A. H., Nicolai, B. M. (2011). Metabolic characterization of tomato fruit during preharvest development, ripening, and postharvest shelf-life. Postharvest Biology and Technology, 62, 7-16. 10.1016/j.postharvbio.2011.04.010

Peel, M. C., Finlayson, B. L., Mcmahon, T. A. (2007). Updated world map of the Köppen-Geiger climate classification. Hydrology and Earth System Sciences Discussions, 4, (2), 439-473.10.5194/hess-11-1633-2007

Pires, A. J. V., Carvalho, G. G. P., Garcia, R. (2009) Fracionamento de carboidratos e proteínas de silagens de capim-elefante com casca de café, farelo de cacau ou farelo de mandioca. Revista Brasileira de Zootecnia, 38, (3), 422-427.10.1590/S1516-35982009000300004

Quadros, P. D., Roesch, L. F. W., Silva, P. R. F., Vieira, V. M., Roehrs, D. D., Camargo, F. A. O. (2014). Desempenho agronômico a campo de híbrido de milho inoculados com Azospirillum. Revista Ceres, 61, (2), 209-218. http://www.ceres.ufv.br/ojs/index.php/ceres/article/view/4097/1930 
Research, Society and Development, v. 10, n. 2, e16710212321, 2021

(CC BY 4.0) | ISSN 2525-3409 | DOI: http://dx.doi.org/10.33448/rsd-v10i2.12321

Repke, R. A., Cruz, S. J., Da Silva, C. J., Figueiredo, P. G., Bicudo, S. J. (2013). Eficiência da azospirillum brasilense combinada com doses de nitrogênio no desenvolvimento de plantas de milho. Revista Brasileira de Milho e Sorgo, 12, (3), 214-226. 10.18512/1980-6477/rbms.v12n3p214-226

Senger, C. C. D., Kozloski, G.V., Sanchez, L. M. B., Mesquita, F. R., Alves, T., Castagnino D. S. (2008). Short communication: Evaluation of autoclave procedures for fibre analysis in forage and concentrate feedstuffs. Animal Feed Science and Technology, 146, 169-174. 10.1016/j.anifeedsci.2007.12.008

Silva, D. J., Queiroz, A. C. (2002). Análise de Alimentos (Métodos químicos e biológicos). 3 ed.UFV, Imprensa Universitária, Viçosa, MG, 165p.

Skonieski, F. R., Viégas, J. Martin, T. N., Nörnberg, J. L., Meinerz, G. R., Tonin, T.J., Bernhard, P., Frata, M. T. (2017). Effect of seed inoculation with Azospirillum brasilense and nitrogen fertilization rates on maize plant yield and silage quality. Revista Brasileira Zootecnia, 46, (9), 722-730. 10.1590/s180692902017000900003

Skonieski, F. R., Viégas, J., Martin, T. N., Mingotti, C. C. A., Naetzold, S.,Tonin, T. J., Dotto, L. R., Meinerz, G. R. (2019). Effect of nitrogen topdressing fertilization and inoculation of seeds with azospirillum brasilense on corn yield and agronomic characteristics. Agronomy, 9, (12), 812. 10.3390/agronomy9120812

Sniffen, C. J., O'Connor, J. D., Van Soest, P. J., Fox, D. G. (1992). A net carbohydrate and protein system for evaluating cattle diets: Carbohydrate and protein availability. Journal of Animal Science, 70, (11), 3562-3577. 10.2527/1992.70113562x

Statistical Analysis System- SAS, Statistical analysis system user’s guide. Cary: Statistics Cary SAS Institute, versão study.

Tangerman, A. \& Nagengast, F. M. (1996). A gas chromatographic analysis of fecal shortchain fatty acids, using the direct injection method. Analytical Bionalytical, 236,1-8.10.1006/abio.1996.0123

Van Soest, P. J. (1994). Nutritional Ecology of the Ruminant. (2a ed.), Cornell University Press, 476 p.

Van Soest, P. J., Robertson, J. B., Lewis, B. A. (1991). Methods for dietary fiber, neutral detergent fiber, and nonstarch polysaccharide in relation to animal nutrition. Journal of Dairy Science,74, 3583- 3597. 10.3168/jds.S0022-0302(91)78551-2

Viana, P. T. V., Pires, V., Oliveira, L. B., Carvalho, G. G. P., Ribeiro, L. S., Chagas, T. D. M., Filho, C. S. N., Carvalho, A. O. (2012). Fracionamento de carboidratos e de proteína das silagens de diferentes forrageiras. Revista Brasileira de Zootecnia, 41, (2), 292-297. 10.1590/S1516-35982012000200009.

Walter, M., Silva, L. P., Perdomo, D. M. X. (2005). Amido disponível e resistente em alimentos: adaptação do método da AOAC 996.11, Alimentos e Nutrição, v. 16, 39-43, https://docplayer.com.br/22490920-Amido-disponivel-e-resistente-em-alimentos-adaptacao-do-metodo-da-aoac-996-11.html

Weatherburn, M. W. (1967). 'Phenol-hypochlorite reaction for determination of ammonia. Analytical Chemistry', 39, 971-974. 10.1021/ac60252a045 